\title{
Reimagining the Fragments of Sappho through Translation
}

\author{
Diane Rayor
}

It is difficult to fix words or meaning on a text in flux. Yet that is precisely what a translator must do: interpret and then set that interpretation into print. In January 2014, I submitted the page proofs for Andre Lardinois' and my Sappho book; the very next day, we found out that a new Sappho papyrus had been discovered. ${ }^{1}$ Fortunately, Cambridge was willing to 'stop the press!'. We waited with the same impatience as everyone else until the $Z P E$ volume provided the Greek text in April, followed by a flurry of translation. The new Sappho discoveries allow us to reinterpret old fragments in light of the additions to them.

While some of the smaller additions merely clarify the previous Greek text or supplement very fragmentary lines, others are more substantial. For instance, fr. 17 initially was missing the left and/or right hand margins of all twenty lines of the poem. The new discovery adds or completes words in ten line endings and sixteen line beginnings. With this significant increase to the Greek text, we can see in what ways previous guesses about meaning fit and what is now proven incorrect. Nevertheless, even with the additions, the poem is still fragmentary, which has led to a wide variety of interpretations of the first stanza. Textual decisions drive interpretations, while, equally, interpretive stances drive textual decisions. As Renate Schlesier (p. 380) succinctly states: 'The textual suggestions are not least shaped by the interpretative conception of the poem, in other words, by the idea each individual scholar advocates concerning what Sappho presumably wanted to express. Translation is an especially intimate and visible active reading in which the reader of the Greek poem becomes the writer of the English poem. ${ }^{2}$

1 Rayor and Lardinois (2014). I presented a shorter version of this paper at the Society of Classical Studies annual meeting, 2015; I am grateful to André Lardinois and Anton Bierl for encouraging me to expand it and for their detailed critique. I also thank Joel Lidov, Eva Stehle, Deborah Boedeker, and Gregory Nagy for their especially helpful comments, and Dirk Obbink for the updated text.

2 Venuti (1995) 18: 'Translation is the forcible replacement of the linguistic and cultural difference of the foreign text with a text that will be intelligible to the target-language reader. This

(C) DIANE RAYOR, 2016 | DOI: 10.1163/9789004314832_020

This is an open access chapter distributed under the terms of the Creative Commons Attribution-

Noncommercial 3.0 Unported (CC-BY-NC 3.0) License. 
This article focuses on the process of re-translating fragments, particularly the striking new readings of the 'Kypris Poem' (formerly known as fragment 26) and of fragment 17. The scholarship that has followed the publication of the texts in April 2014 has again both enriched and narrowed the possibilities for both poems. Most recently, in this volume (ch. 1), Dirk Obbink has corrected the Greek texts again, profoundly affecting the Kypris Poem.

I posit that translations of Sappho, particularly those for readers who cannot consult the Greek, optimally work on three levels: 1 ) The translation invokes the absent song. 2) The translation reads as poetry. 3) The translation evokes the physical fragment on worn or torn papyrus.

To make these multi-layered translations, I have to pay attention to a number of things. To invoke the absent song, I work with sound, and pay attention to signs that could indicate a variety of performance possibilities (such as feminine plurals for choral song or pronoun use). ${ }^{3}$ To insure that the translation reads as poetry, I echo whatever techniques from Sappho that I can make work in English, such as repetition, alliteration, or stanzas. When possible, I help the reader bridge breaks in fragments by selecting words on each side of the gap that work together, as in the Kypris Poem:

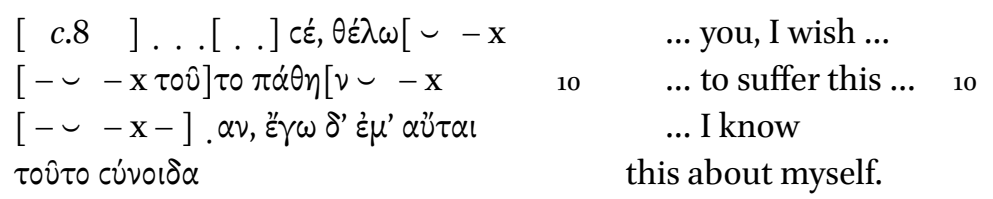

To evoke the physical fragment on papyrus, I employ various strategies, such as brackets, ellipses, and page layout.

Readers of Sappho come to the Greek text with their own expectations of what makes a Sappho poem. Because translators are readers first and then writers of text, translations provide a lens on the storytelling process. ${ }^{4}$ Basically, the translator's reading becomes the new poem. However, I strive to recreate the original as reliably as possible, given that 'no translation will ever be a perfectly reliable guide to the original. ${ }^{5}$ In translating fragments, I imagine

difference can never be entirely removed, but it necessarily suffers a reduction and exclusion of possibilities - and an exorbitant gain of other possibilities specific to the translating language'.

3 Stehle (1997) 262-318.

4 See Rayor (1987) 30-33 and Bassnett (2002) 81-83.

5 Robinson (2003) 6-7: 'A text's reliability consists in the trust a user can place in it ... as a representation or reproduction of the original'. 
the song behind the scraps of words and phrases. Instead of filling in the gaps with guesses, I note in brackets only the most visible editorial suppositions, and let readers fill in the blanks through their own cognitive processes. The mind connects the dots to produce some kind of story: 'The holes in the text are not left empty in the reading process. As we read, we fill in, "read between the lines". 6 This happens even with small scraps, such as we see in fr. $103 \mathrm{~b}:{ }^{7}$

\begin{tabular}{|c|c|}
\hline 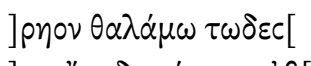 & ... bedroom ... \\
\hline 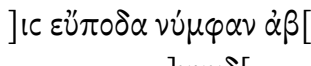 & ... the bride with shapely feet ... \\
\hline $\begin{array}{l}] v 0 v \delta[ \\
] \nu \mu o เ[\end{array}$ & $\begin{array}{l}\ldots \text { now } \ldots \\
\ldots \text { to me } \ldots\end{array}$ \\
\hline
\end{tabular}

The more fragmentary the text, the more difficult it is for the translator to convey song or poem. Some papyrus is too fragmentary to reveal poetry, so I settle for glimpses of the story and the representation of the physical text, the torn papyrus.

\section{Brothers Song}

As illustration, we may examine these three layers with the Brothers Song. When we are blessed with five complete stanzas, much can be done to replicate, or rather imitate, Sappho's gracefulness. Since the first layer is song, I begin with the basic structure of entreaty in Sapphic stanzas, then work with sound by reading the poem aloud in Greek and English. A single word can shape the tone of the fragment. For example, the first extant line of the Brothers Song, that I cite in full below, ${ }^{8}$ begins with $\alpha^{\prime} \lambda \lambda^{\prime} \alpha \ddot{\prime} i \theta \rho \dot{\lambda} \lambda \eta \subset \theta \alpha$ ('but always you keep repeating'), which I render as 'you keep saying':

6 Rayor (1990) 15 .

7 Greek: Aloni (1997) 180.

8 Greek: Obbink (2014b) 37; translation: Rayor and Lardinois (2014) 16o. I follow here the line numbering of the fragment, not of the poem as reconstructed by Obbink in Obbink (2015a) and ch. 1, this volume.

9 The verb $\theta p \dot{\lambda} \lambda \eta c \theta \alpha$ itself implies repeated speech; 'you keep saying' balances repetition without awkward redundancy. 
[1st stanza missing]



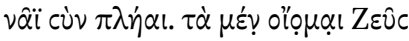



$\tau \alpha \hat{\tau} \alpha$ vónc $\theta \alpha$,



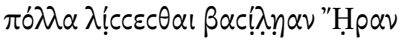



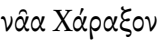

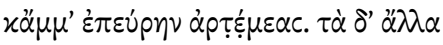

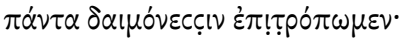

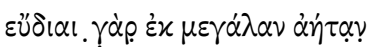

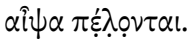

$\tau \hat{\omega} \nu x \varepsilon \beta \dot{o} \lambda \lambda \eta \tau \alpha l \beta \alpha c^{\prime} \lambda \varepsilon v c^{\prime} \mathrm{O} \lambda \nu \dot{\mu} \mu \omega$

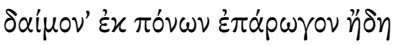
$\pi \varepsilon \rho \tau \rho \dot{\pi} \pi \eta \nu, x \hat{v} \nu 0 \mathrm{l} \mu \dot{\alpha} x \alpha \rho \varepsilon c \pi \dot{\lambda} \lambda \circ \nu \tau \alpha \mathrm{l}$





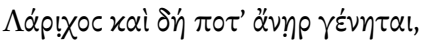

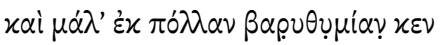

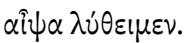

[1st stanza missing]

1 you keep saying that Charaxos must come with his ship full. Zeus knows this, I believe, as do all the gods.

Don't think about that,

but send me, yes command me to keep praying to Queen Hera that Charaxos return here guiding his ship safely

and find us secure. Everything else

10 we should turn over to the gods, since fair winds swiftly follow harsh gales.

Whenever the king of Olympos wishes a helpful god to turn people away

15 from troubles, they are blessed and full of good fortune.

For us too, if Larichos lifts his head high and in time grows into a man, our spirits may be swiftly freed 20 from such heavy weight.

The poem's story implies that the eldest brother Charaxos is late in returning home with his trading ship to the concern of his family, who may depend on the success of his voyage and who also have other troubles at home. The tone is emphatic in its criticism of the addressee, who may be one of Sappho's brothers, either a middle brother (unnamed) or Larichos (named in the last stanza). The rest of the poem progresses logically with Sappho's criticism, followed by her solutions to the problem at hand. ${ }^{10}$ Most translators have rendered $\theta \rho \dot{ }{ }^{\prime} \lambda \eta \theta \alpha$ as 'chatter' or 'babble', which sound overly condescending and rather silly to my ear. Partly, the difference is in understanding Sappho as voicing her critique of the situation or as a scold (which carries baggage in English, particularly as a

10 See Stehle's contribution to this volume (ch. 12). 
label for a woman). Also, in a song, sound matters, so I avoid words that sound ugly or do not fit with the rest of the song.

In addition to sound, layout on the page matters for the second layerpoetry_in translating Sappho. I use the line length in a visibly pleasing and consistent pattern on the page to represent the discipline of the four-verse Sapphic stanza, aiming for the basic pattern best shown in the first, third, and fourth stanzas above." I also work with pattern, rhyme, and repetition to help convey the meaning and emphasis of the original and to help compensate for the loss inherent in translation. For example, the Brothers Song strongly contrasts the 'you' in the first stanza with the 'me' in the second. While the Greek expresses the iterative in two different ways with äï $\theta p \dot{0} \lambda \eta \sigma$ $\theta \alpha$ 'you keep saying' (line 1) and $\pi \dot{o} \lambda \lambda \alpha \lambda \lambda_{i \sigma \sigma \varepsilon \sigma \theta \alpha l}$ 'to pray frequently' (line 6), I make the contrast stand out with 'you keep saying' and 'me to keep praying,' by using repetition and rhyme. In other words, Sappho advocates shifting from repetitive, empty speculation or focus on the potential wealth of her brother Charaxos' return with cargo, to productive prayer for Charaxos' safety: replacing 'saying' with 'praying'. Furthermore, the translation echoes Sappho's redefining of what a successful voyage home means - not with 'his ship full' (line 2) but with 'his ship safely' (line 8). ${ }^{12}$ However, the translation also emphasizes that particular contrast with the repetition of 'full' in 'full of good fortune' for $\pi 0 \lambda$ í $\lambda \beta$ 1 'much wealth or good fortune' (line 12) since Sappho prioritizes her brother's safe return (full of good fortune rather than full of cargo).

Lastly, to indicate the third layer-that Sappho's original Brothers Song is now a fragment missing one stanza-I chose simply to not capitalize the first word, rather than to begin the fragment with 'but' ( $\dot{\alpha} \lambda \dot{\alpha})$. 'But' sounds harsher in English than in Greek, would draw attention away from 'you' (the real subject here), and interferes with the rhythm of the line.

\section{Kypris Song}

The foundation for reliable published translations is accurate Greek texts. However, as we know, the fragments of Sappho's poetry remain in flux. The new Sappho papyri demonstrate the problems, indeed the folly, of relying on

\footnotetext{
11 In Greek, the first three lines have the same meter, followed by a short fourth line.

12 See Nünlist (2014) for the marked contrast between 'with his ship full' and 'with his ship safe'.
} 
reconstructions or uncertain letters for interpreting fragments. Sometimes the uncertainties are more or less resolved: The additions to fr. 5 solve difficulties, confirm guesses, and connect fr. 5 thematically with other family and seafaring poems. $^{13}$

The new Kypris Song, however, radically changes the reading of the old fr. 26 to which it adds. This is my initial rendering in 2013 before the discoveries:

1) (P.Oxy. 1231) fr. 26.1-5:14

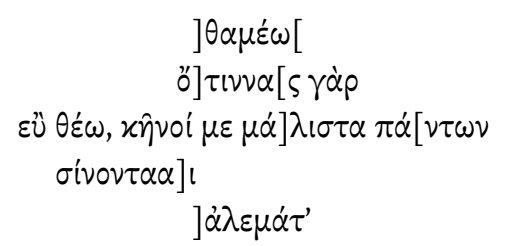

The initial five lines of the Kypris Song overlap (in italics) with fr. 26 sufficiently to show that the previous suppositions were completely incorrect: lines 2-4 are actually the closing lines of another recently discovered fragment (16a). The three stanzas of the Kypris Song address Aphrodite, and focus on the pain of erotic passion.

The Kypris Song presents ongoing textual issues and thus can illustrate the difficulty of settling on one translation. In fact, Dirk Obbink's (ch. 1) contribution to this volume provides a further revised Greek text. The five versions that I present here are in chronological order: 1) my initial rendering in 2013 before the discoveries (above); 2) my first version of Obbink's 2014 text $^{15}$ for the Society for Classical Studies abstract in April 2014; 3) my revision submitted for publication in May 2014; 4) Obbink's latest text (ch. 1, in this volume); and 5) and my latest version in response.

2) In April 2014, I initially ${ }^{16}$ followed Obbink's restorations and interpretation (Kypris Song, 1-6):

\footnotetext{
13 Burris, Fish, Obbink (2014) 11, 23-27.

14 Greek: Campbell (1982a) 76.

15 Obbink (2014b) 49 .

16 Rayor in scs abstract for the 'New Fragments of Sappho' panel.
} 


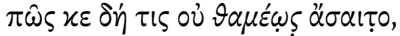

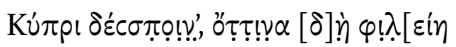

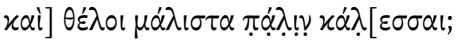
$\pi \circ i]$ है $\chi \eta \sigma \theta \alpha$

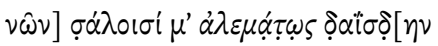
$i \mu \varepsilon \dot{\varepsilon}] \rho \omega \iota \lambda \nu^{\prime}\{t\} \sigma \alpha \nu \tau \iota ~ \gamma o \nu^{\prime} \nu^{\prime} \omega \mu \varepsilon-[\mathrm{x}$
How could someone not keep feeling pain, Queen Aphrodite, wishing most of all to call back the person one loves? [What] do you have

[in mind], to idly rend me [with shaking from desire] loosening [my knees]?

We can view the transition of meaning and tone from the pre-2014 fr. 26 to the new Kypris Song even by examining the two overlapping words: $\theta \alpha \mu \varepsilon$ ' $\omega \varsigma$ 'often/repeatedly' (line 1) and $\alpha \lambda \varepsilon \mu \alpha \dot{\tau} \tau \omega \varsigma$ 'day-dreaming/idly' (line 5). The meaning of $\theta \alpha \mu \varepsilon ́ \omega \varsigma$ remains consistent in the various English renditions. The sole word visible in the P. Oxy. 1231 of fr. 26.5 ( $\dot{\alpha} \lambda \varepsilon \mu \alpha \dot{\alpha} \tau \omega \varsigma)$, however, entertains a wider range of meanings. Each possibility calls up a different image of the speaker and the person she addresses. Before the discoveries, in an attempt to squeeze as much meaning as possible from the fragment, I pictured 'idly' as perhaps 'idle thoughts' or even 'daydreaming'. Yet in the context of the new additions, the word most likely means idle or vain, as in 'to no purpose' 17 and is an adverb referring to Aphrodite. 'Daydreaming' is out.

According to the second translation (above), the lover suffers because of the beloved's absence (such as in Sappho's frs. 16, 94, and 96). However, the order of the phrases or imagery in lyric poetry is important. Here the word and phrase order of the Greek present a more complex idea of passion, in which love itself causes pain and - even so-desire for the beloved. In the first two lines of this fragment, the absence of the beloved does not cause anguish, but rather the anguish is caused by the loved one herself. This happens repeatedly, followed finally by the loved one's absence, as implied in the desire for her return. The paradox is that even with the repetition of pain ( $\theta \alpha \mu \varepsilon \dot{\varepsilon} \omega c$ ăcal third line the speaker wishes most of all to seek that person's return ('whomever

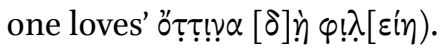

3) Understanding the poem in this way, led to my third version of May 2014 (Kypris Song, $1-3):{ }^{18}$

How can someone not be hurt and hurt again, Queen Aphrodite, by the person one lovesand wishes above all to ask back?

\footnotetext{
17 West (2014) 12.

18 Rayor and Lardinois (2014) 41.
} 
The Kypris poem presents contradictory expressions of love, in which the presence and absence of the loved one cause pain. Although it is a rather complicated argument to follow, this reading follows the Greek text available in May 2014, and aligns with my understanding of the complexity of eros in Sappho. As it turns out, however, part of line 3 in that Greek text is incorrect, and therefore my elaborate argument and translation are wrong as well.

My translation (3) depended upon Obbink's 2014 text (2014b), particularly the third person singular ending of $\varphi ! \lambda[\varepsilon$ in and the entire third line: $x \alpha i] \theta \dot{\varepsilon} \lambda$ ol

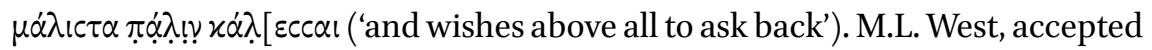
by Franco Ferrari, instead conjectures a negated second person singular verb ( $[\mu] \dot{\eta} \varphi \hat{i} \lambda[\eta c \theta \alpha)$ addressed to Aphrodite and an alternate third line: $x \dot{\omega} c] \theta \dot{\varepsilon} \lambda$ ol

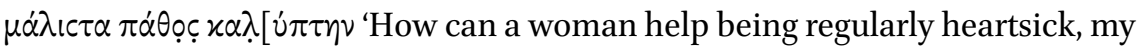
Lady, if you do not love her, and when she would most wish to conceal her passion, you do not hold back.'19 This posits awkward shifting pronouns for the two stanzas and someone wishing to 'conceal passion' - highly unlikely in Sappho's poetry. Renate Schlesier clearly details some of the problems with this reading:

While Ferrari reads vv. 1-4 of the Kypris Poem as one single interrogative sentence, West includes in it also v. 5 and, finding this long sentenceespecially the intervening clause in vv. 2-3-too complicated, suggests another quite odd complication: a change of verb from third person in v. 1 to second person in v. 2 and then back to third person in v. 3 and once more back to second person in vv. 4-5 (all those changes being also adopted by Ferrari). None of this is self-evident. In my view, the option of dividing the first six verses into two sentences (actually two questions, each with a grammatically different subject) of three verses each, the first with three third-person verbs, the second with one single second-person verb, as proposed by Obbink, is defendable ... ${ }^{20}$

Obbink's texts present a generic situation (lines 1-3 someone in love with somebody) followed by one referring to Sappho herself (lines 4-6 'me/Sappho'). ${ }^{21}$ Sappho introduces an indefinite lover hurt by an indefinite beloved before asking Aphrodite a second question addressing her situation. Basically, the West/Ferrari text calls for a strained and awkward reading—even more so than my translation (3) above.

\footnotetext{
19 West (2014) 12 quotation; Ferrari (2014).

20 See Schlesier's contribution to this volume (ch. 17), pp. 380-381.

21 See Benelli (2015).
} 
Obbink's revised Greek text (ch. 1, this volume), on the other hand, makes clear, straightforward poetic sense. Schlesier's ${ }^{22}$ division of the first six verses into two three-verse questions also fits well with the revised text. Here Obbink's translation (4), with the main changes in italics, ${ }^{23}$ is followed by my most recent translation (5):
4) Obbink

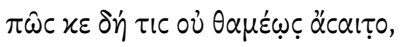

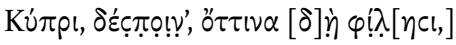

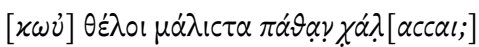

$[\pi \circ \hat{\imath}]$ ० $\varepsilon \chi \chi \eta c \theta \alpha$

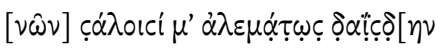

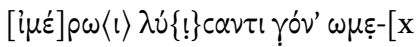

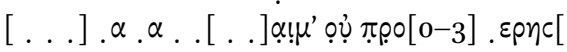

$[-\smile] \nu \varepsilon ฺ \varepsilon p .[.] \alpha !$

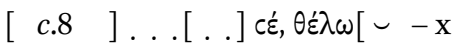

$[-\smile-\mathrm{x} \tau 0 \hat{\nu}] \tau \circ \pi \dot{\alpha} \theta \eta[\nu \smile-\mathrm{x}$

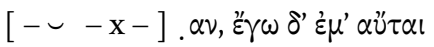

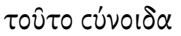

How can someone not be hurt and hurt again, Kypris, Queen, whomsoever one really loves, and not especially want respite from suffering? What sort of thoughts do you have

5 to pierce me idly with shiverings out of desire that loosens the knees ...

... $] \operatorname{not}[\ldots$

...] ...

...] you, I wish $[\ldots$

...] to suffer this ...

... ]. This

I know for myself.

5) Rayor

How can someone not be hurt and hurt again,

Queen Aphrodite, by the person one loves, and not want above all less suffering?

[What] do you have

$5 \quad$ [in mind], to idly rend me shaking

[from desire] loosening my knees?

.. not ...

22 See Schlesier's contribution to this volume (ch. 17).

23 See Obbink's contribution to this volume (ch. 1). 
... you, I wish ...

10

... to suffer this ...

... I know

this about myself.

The importance of using the most up-to-date Greek text is clear, as the revised third line seems to mean almost directly the opposite of the 2014 version (Obbink 2014b): wanting a respite from suffering rather than still wanting to ask the one who inflicts the harm to return. ${ }^{24}$ The poem, as it now stands, poses the question: 'How can someone be repeatedly hurt (line 1), and not want some respite from that suffering (line 3)?' This is not a call for the suffering to end altogether, but for the suffering to go into remission, loosen, relax, for there to be a break, or some relief (among the many word choices I auditioned). The lover wants to suffer less.

The basic sense of lines 1 and 3 are interrupted or modified by line 2; the order of information (word, phrase, or image) matters in Sappho's poetry. Line 2 in word order reads: 'Kypris, mistress, whomsoever indeed one loves'. The line begins with a vocative addressing the love goddess and ends with a love verb, which clarifies what kind of anguish the verb äcal т̣o (line 1) refers to. The direct address to Aphrodite is one of the verbal and thematic overlaps in this poem and fr. 1, in which Sappho prays to Aphrodite to respond to her again concerning matters of love. The feminine $\delta \dot{\varepsilon} \sigma \pi \circ v \alpha$ ('mistress'), which usually refers to a human woman who owns a slave or is mistress of the house, here has the sense of 'my master': 'Whoever is frequently hurt by whomever one loves, Aphrodite, my master, how can that person not want some relief from suffering?'25 The lover resides in lines 1 and 3 , while the causes of suffering (the goddess and the beloved person) physically separate the suffering lover from the lover's desire for respite. Taking the poem step by step, we have: line 1 the person hurt, line 2 Aphrodite and the person causing hurt, line 3 desire for respite. The next three-line question continues addressing the goddess, but moves from a general situation to the speaker specifically: 'Why are you shaking me with knee-buckling desire?'26

24 Although uncertainties remain, the lambda in $\pi \dot{\alpha} \lambda \iota \nu$ (back) is actually the theta in $\pi \alpha \theta \alpha \nu$ (suffering).

25 See Part 3 and Nagy (ch. 21) in this volume for detailed analyses and different interpretations of the Kypris Song.

26 Cf. Sappho fr. 130: 'Once again Love, that loosener of limbs,/ bittersweet and inescapable, crawling thing, seizes me.' Rayor and Lardinois (2014) 77. 
Once I settle on the most plausible Greek text based on scholarship and my own understanding of Sappho, and sketch out potential meaning, then I return to the three-layered process of translating to recreate song, poem, and fragment. Bringing Sappho into English is a difficult balancing act between leading Sappho to the reader, as well as the reader back to Sappho's Greek: 'A translated text should be the site where a different culture emerges.'27 The translation, therefore, gives new life to a poem inaccessible to non-readers of Greek. As Susan Bassnett says, 'The translation effectively becomes the afterlife of a text, a new "original" in another language ... as an act both of intercultural and inter-temporal communication'. ${ }^{28}$ On the one hand, the English version needs to work as English lyric to adequately present Sappho's stunning poetry. On the other hand, it is Sappho's poetry, not the translator's own, and so should be recognizably Sappho's in imagery, argument, order, and form as much as possible - and clearly a translation.

My language choices rest primarily on how the poem sounds aloud, within boundaries of sense and with some kind of consistent vocabulary to represent the Greek. In Sappho's Lyre (Rayor 1991), I replicated Sappho's variation of 'Aphrodite' or 'Kypris'; in Sappho (Rayor and Lardinois 2014), I only use the more immediately familiar 'Aphrodite'. In a more 'foreignizing' translation, I would say 'Kypris, my master' (Kypris Song, 2). ${ }^{29}$ Unfortunately, our gender-biased language resists calling Aphrodite 'master', and 'mistress' has unwanted sexual overtones in English. ${ }^{30}$ 'Queen' at least maintains gender and power. The new line 3 presents a more challenging problem. Although the choice of 'less' does not capture the full sense of $\chi \alpha \dot{\lambda} \lambda \alpha c c \alpha$, it is a better solution in terms of sound in the poem than other possibilities. (Try saying aloud 'respite from suffering' or 'relief from suffering'.)

Translators shape and guide the interpretative options of the Greek source text. By necessity, I choose specific words, phrasings, and format that limit readers of my translations. Yet wherever possible, I attempt to recreate in the translation the openness of the source text to interpretation. I provide the most

27 Venuti (1995) 306.

28 Bassnett (2002) 9 .

29 Venuti (1995) 20: 'Foreignizing translation signifies the difference of the foreign text, yet only by disrupting the cultural codes that prevail in the target language. In its effort to do right abroad, this translation method must do wrong at home, deviating enough from native norms to stage an alien reading experience'. When effective, those disruptions can enhance English poetry.

30 See von Flotow (1997) for more on gender issues in translating; on translating Sappho, $5^{8-63 .}$ 


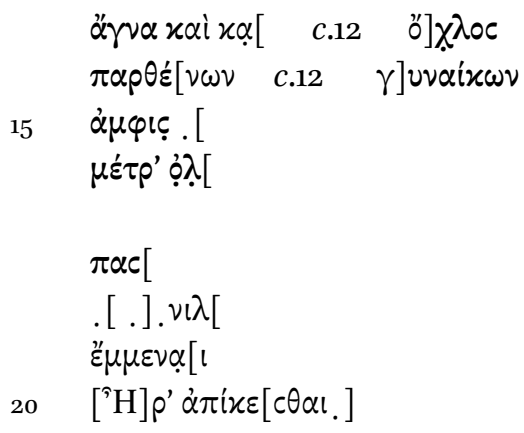

1) fr. 17 Sappho's Lyre (1991)

Queen Hera, may your [graceful form]

... near me-

the prayer of the Atridae ...

kings;

after accomplishing ...

first around [Troy] ...

they departed to this land,

but could not ...

until ... you and Zeus ...

and Thyone's alluring [son].

Now ...

as in [olden times].

Holy and ...

[virgin] ...

2) fr. 17 Sappho (2014)

Near...

your ... festival, Lady Hera,

which the kings had performed

atoning for the son of Atreus

after they had completed great labors, $\quad 5$

first around Troy and later stopping

here, for they could not

find the seaway

before seeking you and Zeus, god of

suppliants, and Semele's alluring son. $\quad 10$

Now ... we too perform

as in those olden days.

Holy and [beautiful] ... throng

of girls ... and women

around ...

measures ...

$$
\begin{aligned}
& \text { every ... } \\
& \text { * } \\
& \text { to be ... } \\
& \text { [Hera] to come. }
\end{aligned}
$$

The new additions to fr. 17 demonstrate how tenuous are our guesses in filling gaps. Primarily, the new text completes lines, providing left and right margins. This makes it possible to follow a narrative that we could only guess at before. In my 1991 translation (1), I open the poem with a prayer for Hera to appear. Joel 
Lidov argues against that reading in a 2004 article and discusses the problem of previous reconstructions of the first stanza:

In current commentaries and translations, the first stanza of fr. 17 is read as a prayer for Hera's presence ... it depends on an improbable use of the opening word $\pi \lambda \dot{\alpha} \sigma i v v$, involves an awkward third-person periphrasis for the second-person appeal, and creates insoluble difficulties of supplementation and usage in the third line. ${ }^{35}$

Lidov then proposes a more plausible reconstruction that frames the opening as a prayer to Hera against storms, and uses the pejorative sense of $\dot{\alpha} \alpha \dot{\alpha} \tau \alpha \nu$ as 'curse'. ${ }^{36}$ This conjecture, in turn, was proven wrong by the new discoveries. $^{37}$

For the translation of fr. 17 shown in (2) above, Lardinois, Lidov, and I wrestled with the possible meanings of the first stanza, and then I shaped our reading into poetry. At that time, Lidov made a persuasive case that the local Lesbian kings held the festival in honor of Hera to atone for Menelaus. If Atreidai is dative singular, it refers to Menelaus here, and 'the kings' are kings of Lesbos. If Atreïdai is nominative plural, however, then the two sons of Atreus (Agamemnon and Menelaus) are the kings. ${ }^{38}$ According to West, the kings are the Atreïdai who founded the festival to Hera in fulfilment of a vow. ${ }^{39}$ Even with the more complete Greek text, many interpretive questions remain, since the Atreïdai could be singular or plural, and àpá $\tau \alpha \nu$ could mean 'prayer,' 'curse', 'atonement', or 'vow'.

Obbink's Greek text of fr. 17 (P. GC inv. 105 fr. 2 col. ii), printed in ch. 1 in this volume, remains almost entirely identical to the previous one. ${ }^{40}$ Here the difference in translations (2) and (3) derives almost entirely from the intervening year of scholarship.

\footnotetext{
$35 \quad$ Lidov (2004) 387.

36 Ibid. 394 .

37 See Burris, Fish, and Obbink (2014) 5-6.

38 Burris, Fish, and Obbink (2014) 19-20 consider both possibilities.

39 West (2014) 4. Neri (2014) 20 argues for Burris, Fish, and Obbink's explanation (2b) of '... which, prayed for, the Atreids, the kings, caused to be performed'.

40 Burris, Fish, and Obbink (2014) 10.
} 
3)

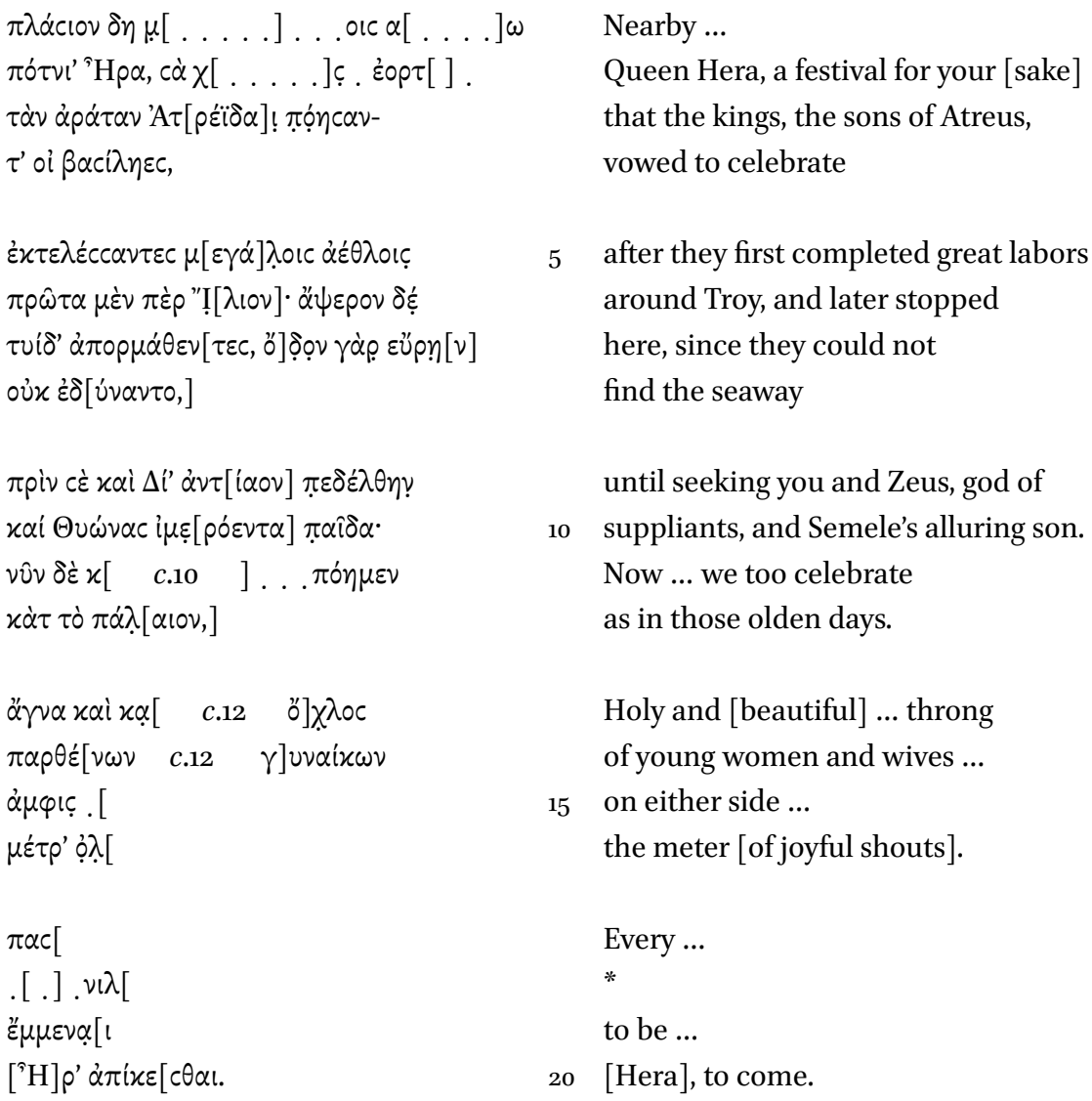

In the second line, Sappho addresses Hera concerning an ancient festival in her honor ('for your sake') ${ }^{41}$ that the Atreïdai (Agamemnon and Menelaos) instituted on Lesbos. ${ }^{42}$ After Troy, they stopped at Lesbos ('here' line 7) for the festival and to pray to Hera-along with Zeus and Dionysus (v. 9-10) - to help them find their way home (line 8). Sappho and others on Lesbos continue to celebrate the festival ('now' line 11) in Hera's precinct. The contemporary festival (lines 11-20) may have included a choral performance of this very song by 'young women and wives' (line 14), joyfully ululating ( $0 \lambda$ [o $0 \lambda v \gamma \alpha \varsigma$ line 16$) \cdot{ }^{43}$

\footnotetext{
41 See Lidov's contribution to this volume (ch. 19).

42 See Nagy's contribution to this volume (ch. 21).

43 See Ferrari (2014) 15.
} 
One of the things that the three translations reveal is the difficulty in representing Greek terms for women in English. Young women of marriageable age, $\pi \alpha p \theta \varepsilon ́ v 01$ (line 14), may be designated as 'virgins' (although not necessarily technically), or 'girls' (young to older teenagers, depending on marriageable age in that location), or 'young (unmarried) women. ${ }^{44}$ The generic word for a woman (gyne) is also 'wife' (particularly one who has already produced a child). The 'throng' (lines 13-14) of women, therefore, includes two groups, marriageable

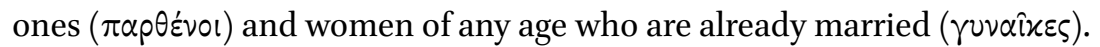

A second concept, $\pi$ ótvi $\alpha$, a term of respect or reverence for a goddess, is also difficult to pin down in English. In my three translations of fr. 17, I went from 'queen' to 'lady' and back to 'queen'. In fr. 1 , I translate $\pi$ 'ó $v i \alpha$ as 'queen' for Aphrodite (since she is on her throne). ${ }^{45}$ Sappho addresses Hera (fr. 17) directly over the other two gods (Zeus and Dionysus) in a festival to Hera, so the power in 'queen' seems appropriate.

Hera's name $\left(\left[{ }^{3} \mathrm{H}\right] \rho^{\prime}\right.$ partly visible on the papyrus in line 20$)$ completes a lovely ring composition with line 2 . When a word is partly visible, the reconstruction fits the available space, and it shows internal consistency with the poem as a whole, then it makes sense to include that word in the translation. In fr. 17.2, the one visible letter chi could be a form of $\chi$ d́p translation (1), I thought it referred to Hera, but the new discoveries proved that wrong. In translation (2), I left it out because it did not seem to fit. For translation (3), I accepted Lidov's argument since the festival is in Hera's honor and 'for your sake' ( $\chi \dot{\alpha} \rho v)$ makes sense grammatically. ${ }^{46}$ In all of these decisions, I aim for directness, as that is how Sappho's poetry speaks to me. ${ }^{47}$ Her poetry, sophisticated and complex, should also ring clear and the sense hit home.

As translator, I aim to activate potential meaning and to reveal the uncertainties of the physical texts, without losing Sappho's poetry. Even the most fragmentary remains can evoke song or at least be read aloud in English. The theory of translation as performance 'conceptualizes translation as a threedimensional activity that not only operates between two languages, but performs the first language in the second language. ${ }^{38}$ My consistent theory of translating is that the experience of reading a translation should be as close as

\footnotetext{
44 See Sissa (1990).

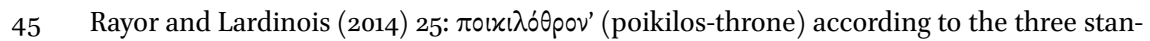
dard Greek texts (Voigt, Campbell, and Aloni) and P. Oxy. 2288, emphasizing her physical position of power.

46 See Lidov's contribution to this volume (ch. 19).

47 See Mendelsohn (2015) 77.

48 Von Flotow (1997) 44.
} 
possible to reading the text in its original language. ${ }^{49} \mathrm{I}$ aim to convey the pleasures of the Greek to a non-Greek-reading audience. Rather than narrowing the range of meaning of these fragments, the conscientious translator allows for options of interpretation as open and rich as those available to readers of the Greek. Each papyrus contains potential and uncertainties. Retranslating Sappho's fragments in light of new finds illuminates the process and demonstrates the need to question previous assumptions to incorporate new discoveries.

Readers come to Sappho with assumptions about Sappho as a historical person, her poetry, performance situations, and the individual poems and fragments. We read each piece as fitting into the overall picture in our minds: the kind of language she uses; the way she ends her poems; whether it is choral, the speaker is Sappho, or is addressed to a circle of women. I picture Sappho performing in multiple venues—sometimes solo, hanging out with a group of female friends or singing for a particular occasion, and other times performing with a chorus of women for festivals or other public events. In a way, the translator is like the Sapphic lover, always choosing between enduring and daring ( $\tau \dot{\lambda} \lambda \mu \alpha \tau o v)$, with experience but no easy answers. ${ }^{50}$ Translations should respect the possibilities of the poems, so that readers can re-create their own Sapphos, based on all the bits of text that still exist.

49 The experience of reading the Greek text is not equivalent to that of the original audience: see Bassnett (2002) 30-36 for the problems of equivalence.

Rayor and Lardinois (2014) 44: fr. 31.17 'Yet all must be endured [dared], since ...' 